\title{
ESTRATEGIAS MIGRATORIAS, RECONFIGURACIONES DE IDENTIDADES CAMPESINAS Y PARTICIPACIÓN EN LA CULTURA ESCRITA
}

\author{
ESTRATÉGIAS MIGRATÓRIAS, RECONFIGURAÇÕES DE IDENTIDADES CAMPONESAS E \\ PARTICIPAÇÃo NA CULTURA ESCRITA
}

\author{
Migrating Strategies, peasant identities' reformulation, ANd Participation in \\ WRITTEN CULTURE
}

Elisa Rita Cragnolino

Licenciada y Profesora en Historia, Universidad Nacional de Córdoba, Doctora en Antropología, Universidad de Buenos Aires. Profesora regular, Facultad de Filosofía y Humanidades, cátedra de Sociología y Teoría Social, maestría en Investigación Educativa, doctorado en Estudios Sociales Agrarios. Centro de Investigaciones María Saleme de Burnichón, Universidad Nacional de Córdoba, Argentina.

Baiorri 584 (5000) Córdoba

elisag@ffyh.unc.edu.ar
Proyecto "Educación Básica Rural y de Jóvenes y Adultos. Políticas, actores y prácticas". Institución que acredita y financia la Agencia Nacional de Investigación Científica y TecnológiCa - FONCYT- convocatoria proyectos Bicentenario (2010) "Temas abiertos" PICT-2010-0890, periodo 2011-2015. Fue dirigido por Elisa Cragnolino y codirigido por Maria del Carmen Lorenzatti

\section{RESUMEN}

En este artículo retomo análisis resultantes de trabajos teóricos y empíricos referidos a las prácticas de cultura escrita en territorios rurales de Córdoba (Argentina). En este caso, enfoco mi atención en las estrategias migratorias desplegadas por las familias campesinas del norte de esta provincia, para reflexionar acerca de cómo se incorporan en ellas las prácticas de lectura y escritura. Analizo el lugar que las estrategias migratorias tuvieron en la reproducción social de las familias a lo largo de varias décadas del siglo xx poniéndolas en relación con las transformaciones estructurales y políticas y los procesos de descampesinización, para detenerme luego en el análisis de los procesos de configuración-reconfiguración de identidades de estas familias. Esto me permite poner en discusión visiones que en los ámbitos escolares presentan estas identidades y prácticas culturales campesinas como estáticas, ahistóricas e inhabilitantes en términos de acceso a la educación y a la cultura escrita. En este análisis me resultan fértiles las convergencias entre los Nuevos Estudios de Literacidad y el enfoque de la sociología de Pierre Bourdieu en cuanto ambos permiten entender cómo las prácticas de cultura escrita son construidas socialmente, históricamente situadas, desigualmente distribuidas e insertas en el marco de otras prácticas y relaciones sociales que les otorgan sentido. En ambos enfoques la clave está puesta en considerar la lectura y escritura no como una variable independiente, aislada, sino como una práctica social y parte de una trama de relaciones que se reconfiguran en espacios locales y en el tiempo.

Palabras claves: familias campesinas; cultura escrita; estrategias migratorias; identidades.

\section{RESUMO}

Neste artigo retomo análises resultantes de trabalhos teóricos e empíricos referidos às práticas de cultura escrita em territórios rurais de Córdoba (Argentina). Neste caso, enfoco minha atenção nas estratégias migratórias exercidas pelas famílias camponesas do Norte desta província, para reflexionar sobre como se incorporam nelas as práticas de leitura e escritura. Analiso o lugar que as estratégias migratórias tiveram na reprodução social das famílias ao longo de várias décadas do

Received: 2018-09-24/ Accepted: 2019-02-01/ Published: 2019-05-20

DOI: $10.17533 /$ udea.ikala.v24n02a03 
século xx colocando-as em relação com as transformações estruturais e políticas e os processos de descamponização, para focar logo na análise dos processos de configuração-reconfiguração de identidades destas famílias. Isto me permite pôr em discussão visões que nos âmbitos escolares apresentam estas identidades e práticas culturais camponesas como estáticas, ahistóricas e incapacitantes em termos de acesso à educação e à cultura escrita. Nesta análise resultam-me férteis as convergências entre os Novos Estudos de Letramento e o enfoque da sociologia de Pierre Bourdieu as quais permitem entender como as práticas de cultura escrita são construídas socialmente, estão historicamente situadas, desigualmente distribuídas e se produzem no âmbito de outras práticas e relações sociais, que lhes outorgam sentido. Em ambos enfoques o crucial está no sentido de considerar a leitura e escritura não como uma variável independente, isolada, senão como uma prática social e parte de uma trama de relaçôes que se reconfiguram em espaços locais e no tempo.

Palavras-chave: famílias camponesas; cultura escrita; estratégias migratórias; identidades.

\section{Abstract}

In this paper, I review analyses resulting from empirical works referred to written practices in rural areas in Córdoba (Argentina). In this case, I will focus on migratorystrategies deployed by peasant familiesfrom the northern part of the province, aiming to reflect upon their incidence in adopting reading and writing practices. I will analyze the role these migratory strategies had on family social reproduction throughout several decades of the $20^{\text {th }}$ century, relating them to structural and political changes, and depeasantization processes. Then I will delve into processes of identity building-rebuilding within these families. This allows me to bring to discussion some views often encountered in school settings, presenting peasant identities and cultural practices as static, ahistorical and incapacitating regarding access to education and written culture. To carry out this analysis I found revealing insights in the New Literacy Studies and Pierre Bourdieu's sociological approach, since they both helped me to understand how written practices are socially constructed, historically situated, unequally distributed, and occurring within the framework of other practices and social relationships that give them meaning. In both approaches, the key is to consider reading and writing not as independent isolated variables, but as a social practice and a part of a web of relations reconfiguring themselves across local spaces and throughout time.

Keywords: peasant families; written culture; migratory strategies; peasant identities. 


\section{Introducción}

En este artículo ${ }^{1}$ retomo el análisis resultante de trabajos teóricos y empíricos referidos a las prácticas de cultura escrita en territorios rurales de Córdoba (Argentina). En este caso, enfoco mi atención en las estrategias migratorias desplegadas por las familias campesinas del norte de esta provincia, para reflexionar acerca de cómo se incorporan en ellas las prácticas de lectura y escritura. Analizo el lugar que las estrategias migratorias tuvieron en la reproducción social de las familias a lo largo de varias décadas del siglo Xx poniéndolas en relación con las transformaciones estructurales y políticas y los procesos de descampesinización para detenerme en el análisis de los procesos de configuraciónreconfiguración de identidades de estas familias, considerando distintos momentos históricos. Esto me permite poner en discusión ciertas visiones que en los ámbitos escolares presentan las identidades y prácticas culturales campesinas como estáticas, ahistóricas e inhabilitantes en términos de acceso a la educación y a la cultura escrita. Las indagaciones antropológicas con perspectiva histórica muestran, en cambio, una inclusión progresiva en la cultura escrita, al menos de algunos miembros de estos grupos. Según lo hemos anunciado esta participación estará vinculada, en un principio, con la estrategia de salida de los hijos de la zona rural. Mientras que en las últimas dos décadas, a partir de la emergencia de un movimiento campesino, se vinculará con la apuesta de permanencia en el campo, la construcción de una nueva identidad y el despliegue de disputas políticas y culturales, donde la lectura y la escritura asumen un nuevo lugar.

1 Este trabajo constituye una versión revisada y ampliada de desarrollos de una ponencia inédita presentada en la mesa redonda "Práticas culturais, diversidade e identidades", en el v Coloquio Internacional Letramento e Cultura Escrita: Contraposição e integração de estudos sobre letramento e cultura escrita: Um balanço interdisciplinar, Faculdade de Educação, Universidade Federal de Minas Gerais, Belo Horizonte, Brasil, del 12 al 14 de agosto de 2014.
En este análisis me resultan fértiles los postulados de los Nuevos Estudios de Literacidad y la sociología de Pierre Bourdieu, dado que permiten entender cómo las prácticas de cultura escrita son construidas socialmente, históricamente situadas, desigualmente distribuidas, y producidas en el marco de otras prácticas y relaciones sociales que les otorgan sentido.

\section{El reconocimiento de las prácticas de cultura escrita: articulando a Bourdieu con los NEL}

En este apartado me referiré a algunas cuestiones teóricas y metodológicas surgidas de las investigaciones que detallo a continuación. El programa de investigación y extensión que coordino (PIERJA) ${ }^{2}$ ha estudiado los procesos de acceso y apropiación de la educación y la cultura escrita en familias campesinas. Nos interpela la pobreza rural y campesina y las maneras como sistemáticamente se define y estigmatiza a estos niños, jóvenes y adultos. Buscando herramientas teóricas que nos permitan comprender estos procesos recurrimos al sociólogo francés Pierre Bourdieu, para pensar en intervenciones desde el espacio universitario, sobre todo en proyectos de formación de docentes del sistema educativo y educadores de organizaciones sociales. ${ }^{3}$ Discutimos un cierto sentido común cristalizado que atribuye la pobreza rural al "analfabetismo"; define a los campesinos por sus carencias y no reconoce los conocimientos que tienen y cómo participan en eventos de lectura y escritura. Estos discursos, según lo vemos en nuestros trabajos de campo, están en boca de muchos docentes y funcionarios que interpretan de este modo los "fracasos educativos" de niños,

2 Programa de investigaciones Educación en Espacios Sociales Rurales y Educación Básica de Jóvenes y Adultos. CIFFYH, facultad de Filosofía y Humanidades. UNC, creado en el año 2006, cuya coordinación comparto con la doctora María del Carmen Lorenzatti. Comprende dos grandes líneas de trabajo, donde yo estoy a cargo de los estudios sobre educación en los espacios rurales.

3 Cfr. Cragnolino (2011). 
jóvenes y adultos en las escuelas rurales, y señalan las dificultades de revertir la situación por la "falta de conocimientos" y de recursos de lectura y escritura que tendrían las familias.

En un artículo anterior (Cragnolino, 2009) argumentamos que en estas explicaciones se hacen visibles enfoques que consideran la pobreza y el analfabetismo como "rémoras del pasado", situaciones que serían "incompatibles con el mundo moderno"; "problemas individuales", "déficits" que se resolverían "técnicamente", pero lo que planteamos aquí es que en la medida en que sigamos considerando a los campesinos de este modo, como "no integrados" y "atrasados", en cuanto se esencialice y reifique la condición de pobreza y la de analfabetismo que aparece asociada lo campesino, y no se tenga en cuenta que estas condiciones han sido socialmente construidas y están enraizadas en relaciones de poder y en condiciones estructurales y simbólicas, no vamos a poder construir conocimientos y estrategias educativas "inclusivas" que garanticen el cumplimiento de los derechos a la educación.

En Argentina están vigentes desde la década de 1990, pero sobre todo desde fines de 2006, con la promulgación de la Ley de Educación Nacional 26206, ciertas políticas fundamentadas en la diversidad y la interculturalidad, orientadas a colectivos sociales alejados de los parámetros de socialización hegemónicos, entre ellos los rurales. Como señala Novaro (2011), el desafío es “identificar y eventualmente apoyar reflexivamente, sus elementos de crítica a las propuestas homogeneizadoras, pero también para precisar sus sentidos potencialmente funcionales a la fragmentación y la segmentación educativa" (p. 25). En esa línea cabe preguntarnos si y de qué modo ciertas políticas que se focalizan en determinados sectores, en este caso "la ruralidad", estarían bajando las expectativas sobre aquello que es posible enseñar y aprender, y de este modo harían "más invisibles y matizadas, las formas de exclusión de aquellos a quienes se pretende incluir" (Novaro, 2011, p. 25).
La cuestión es compleja porque nuestras investigaciones y actividades de extensión universitaria mostraron que existieron y existen espacios de literacidad de una gran riqueza en el campo, la cual es frecuentemente desconocida, no solo en los ámbitos escolares. Los integrantes de las familias campesinas que fueron objeto de estudio también presentaban a la comunidad rural y sus hogares como ambientes "iletrados", que se corresponderían directamente con "la pobreza", "la falta de entendimiento", "la ignorancia", "el trabajo de gente bruta". Solo reconocían la escuela como el "lugar de las letras".

A pesar de la invisibilización de estos recursos de cultura escrita, durante nuestro trabajo etnográfico, con la permanencia en la casa, el acompañamiento a las actividades domésticas y prediales, a través de entrevistas e historias de vida y la indagación en archivos escolares, aparecieron evidencias de la existencia de diversos materiales de cultura escrita y de la inclusión de los integrantes de las familias en eventos y prácticas letradas. ${ }^{4}$ Estas se configuraban con relación no solo a los espacios escolares, sino también a la organización doméstica, el trabajo en la chacra y con los animales, la migración, la actividad religiosa, política y comunitaria.

La investigación mostró además que la participación en la cultura escrita se fue modificando conforme se producían transformaciones en las estrategias de reproducción social campesina, entre ellas las migratorias, a lo que nos referiremos en un próximo apartado. Como lo han planteado los New Literacy Studies, ${ }^{5}$ esa invisibilidad de la cultura escrita es parte

4 Barton y Hamilton (1998) describen los eventos de literacidad como las actividades observables en los que la lectura o la escritura se desarrollan. Estas actividades siempre están insertas en contextos sociales y emergen de prácticas de literacidad que constituyen formas culturales para usar el lenguaje escrito. A diferencia de los eventos, las prácticas no son directamente observables, ya que incluyen una serie de valores, actitudes, sentimientos y relaciones sociales.

5 Véase, entre muchos otros, Street (1993, 2003, 2005), Barton y Hamilton (1998); Barton e Ivanic (1991); Kalman (2004); Zavala (2002, 2005). La versión en español de textos centrales de los NEL puede verse en Zavala, 
de los entramados de poder que deben ser analizados en los diferentes casos. Aquí encontramos una de las varias coincidencias que esta perspectiva tendría con el enfoque de Pierre Bourdieu. Una preocupación que atraviesa toda la obra del sociólogo francés es justamente la comprensión de los mecanismos de perpetuación del orden social y los modos de dominación. Los desarrollos por los que es más conocido, al menos en los ámbitos académicos argentinos, tienen que ver con sus análisis acerca del lugar de la escuela y los procesos escolares como reproductores del capital cultural y su relación con la reproducción de las relaciones de clase — relaciones de dominación objetivas y simbólicas- (Bourdieu y Passeron, 1977). El acento que pone Bourdieu en las obras posteriores a La reproducción (Bourdieu y Passeron, 1977) sobre la génesis social y procesual de los campos, la capacidad inventiva y estructurante del habitus y la relación también histórica entre campo y habitus, la noción de trayectorias, sus estudios sobre los procesos de desclasamiento, reenclasamiento, reconversión de capitales, en el marco de estrategias de reproducción social (en adelante, ERS), no pueden pasar inadvertidos, en cuanto nos permiten analizar prácticas y procesos de cultura escrita. ${ }^{6}$ Las ERS se entienden como ese conjunto de prácticas por medio de las cuales los individuos y las familias tienden de manera consciente o inconsciente a conservar o mejorar su

Niño-Murcia y Ames (2004) y en Cassany (2006), quien desde España desarrolla la perspectiva sociocultural de la lectura y la escritura.

6 Mencionamos, entre muchas otras, "Porvenir de clase y causalidad de lo probable, a conservar o aumentar su posición en la estructura de las relaciones de clase," y "Enclasamiento, desclasamiento, reeenclasamiento, publicados originalmente en 1974 y 1978, respectivamente, y en una versión más reciente en español como parte del libro Las estrategias de reproducción social (2011). En la misma obra, véase la interesante Introducción elaborada por Alicia Gutiérrez. También el reconocido libro $\mathrm{La}$ distinción. Bases sociales del gusto ( $1 .^{\mathrm{a}}$ edición en francés en 1979) donde desarrolla en extenso la noción de estrategias de reproducción. Nos podemos dejar de nombrar también El sentido práctico (1. ${ }^{a}$ edición de 1980), entendido por ciertos analistas como un texto fundamental y bisagra en la obra de Bourdieu. posición en la estructura de las relaciones de clase (Bourdieu, 1988). Entendemos que pensando en las categorías enunciadas por Pierre Bourdieu es posible comprender las formas particulares y significativas que asumen las prácticas de lectura y escritura en distintos contextos y dilucidar cómo proveen o no acceso a recursos y oportunidades. A continuación voy a detenerme en una de las ERS, las estrategias migratorias, para pensar cómo se incorporan las prácticas de lectura y escritura en relación con ellas.

\section{Del autoabastecimiento predial al abandono del campo}

Es así acá, uno ya sabe. Tiene hijos y descué se van, pero es para el bien de ellos. Para que no sean como nosotros, gente de campo, así no más, sin cultura. Si vos vas a preguntar: en todas las casas hay que se fueron. A veces quedan los padres solos. ¿Qué le va a hacer? Para quedarse burreando acá, mejor que se vayan. (Rosa, comunicación personal, Tulumba, 1998)

El fragmento anterior es una de las tantas expresiones que recogimos en nuestro trabajo de campo realizado en los últimos años de la década de los 90 con familias de origen campesino, en el norte de Córdoba, Argentina. Formando parte de su historia e incorporada a su sistema de habitus y representaciones, la migración se presentaba para los miembros de las unidades domésticas del departamento de Tulumba como una experiencia "necesaria", una salida "natural", y como un proceso inevitable y prácticamente irreversible.

El norte cordobés es una zona que históricamente ha sido campesina. En las primeras décadas del siglo Xx las familias en los pequeños predios se autoabastecían a través de la cría de caprinos y, en menor medida, de vacunos, y del cultivo de maíz y zapallo en las pequeñas chacras y la recolección y procesamiento de frutos del monte. Me estoy refiriendo a una región extrapampeana de menor desarrollo capitalista relativo, pero que paulatinamente se fue incorporando al mercado de trabajo, consumo y producción. Las características agroecológicas, zonas semiserranas y con desmonte progresivo, fueron limitando esa diversificación productiva; los 
predios se subdividían por la herencia y las familias comenzaron a vender fuerza de trabajo estacional para el agro capitalista. Las migraciones se enmarcaban en la alta disponibilidad de mano de obra familiar y se vinculaban con las limitadas posibilidades de seguir repartiendo la tierra entre los hijos, sin que se afectara la viabilidad económica de la unidad. También se relacionaban con la intención de procurar recursos alternativos; sobre todo en la medida en que se incrementaba la monetarización de la economía campesina por la llegada de servicios y la compra de productos manufacturados que reemplazaran la producción doméstica.

A partir de los años 50 se reorientó la migración: ya no solo sería rural, sino fundamentalmente urbana; dejaría de ser estacional y se haría estable y definitiva, lo cual coincidió con dos cuestiones: por un lado con las importantes posibilidades de empleo en las ciudades, vinculadas con la política de sustitución de importaciones, el desarrollo industrial y de servicios y un estado de bienestar redistribucionista durante las dos presidencias de Domingo Perón (1946/1955), que facilitó la radicación de la gente del campo. Por otro lado, con el avance tecnológico en la zona pampeana se produjo en la década del 60 el reemplazo de mano de obra por maquinaria, con lo que se limitaron las posibilidades de las familias de obtener recursos monetarios a través de las salidas transitorias con destino rural.

El seguimiento de los censos poblacionales y agropecuarios y los testimonios recogidos en el campo permiten advertir este proceso de despoblamiento desde los años 60, que se incrementaba paralelamente a la reducción de tamaño de los campos y rebaños, mientras las grandes explotaciones capitalistas avanzaban. La pobreza en la región se agudizó con el impacto de la crisis económica, la liberalización de la economía y el retiro del Estado de los años 90.

En la actualidad la zona se ve fuertemente impactada por las consecuencias derivadas del agronegocio vinculado a la producción de soja transgénica, que ha producido el corrimiento de la frontera agraria y la incorporación a la siembra directa de grandes extensiones que antes por el régimen de lluvias no se dedicaban a la agricultura, con lo cual se ha trasladado parte de la producción ganadera capitalista que se encontraba más al sur de estas zonas, hacia las anteriormente consideradas "marginales" del norte cordobés. Se ha extendido así el desmonte indiscriminado y la concentración productiva, con el consiguiente desplazamiento territorial de la producción campesina y los conflictos por la tierra. Esta expansión capitalista se produjo mediante la compra a uno o todos los herederos, pero también a través, cada vez más, de la apropiación ilegal de tierras sin títulos por parte de empresarios, en complicidad con representantes del poder político, judicial y la policía.

Frente a estas situaciones las poblaciones campesinas comenzaron a organizarse y a adelantar procesos de resistencia y de lucha. Varias organizaciones se agruparon en el Movimiento Campesino de Córdoba (2010) con el ánimo de resolver colectivamente sus problemas relativos a la producción y comercialización, el mal estado de los caminos, la falta de agua, los conflictos de tierras y la criminalización por parte del Estado a los pequeños productores que se resisten a ser desalojados. También se organizaron para resolver cuestiones relativas a la salud y la educación. A estas cuestiones nos referiremos más adelante.

\section{Espacios formativos, estrategias migratorias y sus vinculaciones con las prácticas de cultura escrita}

Las transformaciones estructurales y simbólicas que hemos mencionado produjeron cambios en las estrategias campesinas, redefinieron los mecanismos de sostenimiento y reproducción generacional y social y las identidades construidas. En relación

7 Sobre este último proceso, véase Cragnolino (2009), donde interpelamos explicaciones que se realizan relacionando y justificando la posibilidad de la expropiación de tierra campesina por el analfabetismo de los antiguos dueños y legítimos poseedores. 
con las estrategias educativas se produjeron rupturas respecto a los espacios formativos considerados necesarios y ventajosos. Los hijos eran, y son en la actualidad, sometidos a aprendizajes tempranos acerca del trabajo doméstico y predial a través la observación y luego la imitación, lo que les permitía apropiarse paulatinamente del repertorio de conocimientos especializados que les servirían para resolver problemas "prácticos" (el conocimiento de los ciclos climáticos, las operaciones necesarias para el cultivo y la cosecha, el manejo de los instrumentos, las enfermedades de los animales, las rutinas de la cocina y los quehaceres de la casa). En estos procesos están ausentes la lectura y la escritura. "Era todo de palabra, mirar y hacer" (Rosario, entrevista, San José de la Dormida, marzo de 1996).

Estas tareas, realizadas bajo la supervisión de los adultos, no solo contribuían al funcionamiento de la unidad campesina y los preparaban para el trabajo futuro; también eran la manera como se transmitían las "verdades" compartidas", un conjunto de representaciones acerca de sí mismos y de los demás; objetivaciones de la realidad, desde las cuales se interpretaban las prácticas y se les otorgaba sentido. Se buscaba también de que se apropiaran de "una conducta", maneras de comportarse y actitudes hacia la vida, que estaban dirigidas a garantizar un "adecuado" desempeño" en el trabajo, en la familia y en la vida comunitaria. Estas prácticas y sentidos ayudaban a conformar la identidad de la "gente del campo", como se llamaban a sí mismos.

Con el auge de las estrategias migratorias y cuando se hacía evidente que los hijos abandonarían los predios, los esfuerzos familiares en materia educativa se orientaban a garantizar también el acceso y la permanencia en la escuela; primero solo de algunos de los niños, y por un tiempo limitado, hasta el momento en que obtuviesen algunos conocimientos mínimos en lectoescritura y cálculo, que les permitieran "defenderse mejor" al intentar la inserción laboral fuera del predio. Comenzó a ser importante entonces "saber firmar", "saber leer y hacer cuentas" para que no los engañaran, por ejemplo, los contratistas que los llevaban a las cosechas, los patrones en la pampa, las patronas de servicio doméstico, o los dueños de "boliches" (almacenes) y los comerciantes ambulantes que llegaban a la zona y los proveían de "mercaderías".

Reconociendo su propia incapacidad para transmitir estos conocimientos, la familia empezó a delegar estas actividades formativas a los maestros, quienes eran además un referente urbano y por ende podían enseñarles no solo de letras y números, sino también una "manera de ser gente" y desenvolverse adecuadamente en la ciudad. De este modo, el manejo de la lectura y escritura empezaba cada vez más a ser pensado como un medio de habilitación social; el saber leer y escribir abría a la "consideración" de los otros, les permitía hacerse visibles, y de algún modo protegía o ponía en mejor posición a su portador. Como señalaba Rosa “...teníamos que aprender a leer y escribir para que no los miren a menos,... para que lo consideren, porque si no sabe leer no lo consideran..." (Rosa, comunicación personal, San José de la Dormida, mayo de 1996).

Hay aquí también toda una caracterización que remite a la condición e identidad de "la gente del campo" y que liga ser del campo con el trabajo del campo, el cual a su vez se presenta como una tarea de "brutos", "de pobres", "sucio", "sin horarios ni descanso" a lo largo de todo el año, y prefigura un futuro que no desean para sus hijos. El trabajo del campo se opondría al de la ciudad, "más descansado", "limpio", con "mejor pago" y sobre todo "con futuro". Las opciones de cambio y movilidad social las encontraban en los empleos no rurales; en oficios, en las fábricas o comercios. En este sentido, las familias tenían progresivamente referentes exitosos entre los familiares y amigos que se establecían en la ciudad.

Si envían a los chicos a la escuela es para que "sean otra cosa", "para que tengan una vida mejor" y por eso más adelante muchos no estarían de acuerdo con que en la escuela primaria la maestra les enseñara a hacer una huerta. Porque los chicos van a 
la escuela para aprender sobre aquello que su familia no puede enseñarles. "No tienen que perder tiempo... van por las cuentas y las letras" (Raúl, La Toma, mayo de 1997), nos decían.

$\mathrm{Y}$ aquí aparece otra cuestión interesante que tienen que ver con que el reconocimiento de que los saberes productivos no necesitan ni de letras, ni de libros. Porque del campo se aprende solo en el campo.

"No me va a venir a enseñar la maestra como [sic] plantar o el profesor ese del IPEA ${ }^{8}$ de los animales y maíz. ¿Qué quiere enseñar? ... Siempre se trabajó igual, mucho para enseñar no hay" (Raúl, 1997)

Aunque los padres no supieran qué tipo de conocimientos específicos estaban implicados en el "manejo de las letras", reconocían su importancia y pensaban que, con el esfuerzo, y cumpliendo con las tareas asignadas por la maestra, saldrían adelante. Si bien en general lo que nuestros entrevistados destacaban eran las dificultades, la ausencia de tiempo y conocimientos de los padres para acompañarlos, y la inexistencia de libros y manuales escolares, en algunos de los casos analizados, los testimonios muestran cómo padres analfabetos supervisaban los deberes escolares, imponiendo una suerte de ritual al anochecer, cuando se "revisaban" los cuadernos. Así, nos decía Mabel:

Mi mamá nos sentaba a la mesa que la limpiaba mucho, mucho antes, y se quedaba ahí y nos vigilaba... Nos exigía la letra... todo derechito sin salirse del renglón... Ella poco sabía, pero era exigente así de... porque ella no fue casi a la escuela, se murió su mama y a ella la llevaron más a otro campo, pero le quedó eso de la prolijidad, de la letra y [en] eso se fijaba”. (1997)

Pero la vigilancia del "deber escolar" se ejercía no solo sobre los chicos, sino también sobre los maestros. Hemos recuperado testimonios, pero también documentos en los archivos escolares, acerca de la vigilancia que las familias ejercían sobre los docentes

8 Instituto Provincial de Educación Agropecuaria, que corresponde a la escolaridad secundaria del sistema escolar de la provincia de Córdoba. en los casos en que faltaran durante mucho tiempo y no cumplieran con sus obligaciones de enseñar. Justamente estas situaciones daban lugar a reclamos que se vehiculizaban a través de presentaciones escritas ante los inspectores zonales y regionales, en cuyo caso había que redactar textos y sobre todo gestionar la documentación de modo que llegara a los lugares donde pudieran obtener respuestas, es decir, en toda esta tramitación había habilidades y conocimientos que no tenían que ver necesariamente con saber leer y escribir, sino con la gestión de los papeles y con la existencia de un capital social y político que se movilizaba. Estas personas, todos hombres, en algunos casos no sabían las letras, pero sí sabían qué hacer con los papeles y cómo y a dónde hacerlos llegar.

La habilidad de leer y escribir, la familiaridad con los documentos y oficios o el "saber qué hacer con los papeles” eran, en las familias campesinas estudiadas, bienes escasos y se convirtieron en un capital importante que ayudaba a mantener o mejorar la posición social de la familia en la trama de poder local. Algunos de estos documentos fueron conservados y pudimos tener acceso a ellos, lo que habla además de la importancia que se les concedía a los mismos. Y esto sucedió sobre todo a medida que avanzaban las comunicaciones con el exterior, llegaban servicios y productos y se incrementaban las estrategias migratorias.

Las "salidas" ${ }^{10}$ estacionales para el trabajo en las cosechas, o más prolongadas y estables, en las ciudades fueron para los migrantes espacios de adquisición de conocimientos sobre lectura y escritura y ocasión de participación en eventos letrados. En el caso de los varones un tipo de desplazamiento fuera del campo familiar fue el vinculado con "la colimba". Aquellos jóvenes quellegaban al servicio militar obligatorio sin haber pasado por la escuela, o lo habían

9 Véase al respecto Cragnolino (2013).

$10 \mathrm{La}$ "salida" del campo, el "irse" y "el volver" son categorías nativas que nuestros entrevistados usaban. En ningún caso daban a ese traslado propio, de familiares o vecinos la categoría de migraciones. 
hecho durante tan poco tiempo que no habían aprendido a "manejarse con las letras", tenían la oportunidad de acceder a esos conocimientos.

Para las muchachas criadas en el campo las primeras experiencias migratorias eran a destinos urbanos, para incorporarse en el mercado de trabajo informal como empleadas domésticas. Este empleo supuso un punto de inflexión en las vidas de nuestras entrevistadas, ya que fue la primera vez que se alejaron de la familia y que contaron con ingresos propios; pero además, según lo rememoran, las habría provisto de nuevos conocimientos y oportunidades. Uno de los que mencionan tiene que ver con el contacto con el "mundo letrado". La necesidad de seguir listas de compras, tomar recados, poder leer notas con indicaciones de las patronas, moverse en la ciudad, tener acceso cotidiano a revistas y diarios, y escribir cartas a los familiares habría impulsado en algunas de nuestras entrevistadas la necesidad de adquirir o reforzar conocimientos sobre las letras.

Por medio de los migrantes, llegaban al campo materiales de cultura escrita, revistas, folletos y en algún caso nos mostraron notas tomadas por los jóvenes migrantes acerca de cómo producir más eficientemente, organizar las cuadrillas para el trabajo de siembra y cosecha o el manejo de los vacunos. Nos preguntamos si el paso a la escritura no podría pensarse como estrategia de legitimación que ponían en juego algunos de los hijos al momento de volver a sus hogares y a la hora de lidiar con las formas tradicionales del trabajo paterno. Hago este planteo, porque la migración supone tensiones. Según nuestras evidencias, se trata de un momento disruptivo para las unidades familiares; en varios sentidos, porque al momento de la partida hay que reorganizar el trabajo para reemplazar al que se fue, pero también porque al regreso los hijos se plantean seguir trabajando para el padre o independizarse. También se ponían en tensión formas de producir, establecidas con nuevas experiencias y conocimientos que traían los jóvenes luego de su paso por el trabajo asalariado en la zona pampeana.
Planteamos que las experiencias migratorias también ayudan a reconfigurar la manera como las nuevas generaciones se conciben a sí mismas como "gente del campo". Por lo tanto, pueden plantearse como un espacio de reconfiguración de identidades; no pensando que se reemplaza una identidad por otra, sino que en esta nueva etapa convergen, y se articulan de manera compleja, diferentes referentes identitarios. Seguimos en este sentido a Stuart Hall (2003), entre otros, al cuestionar los esencialismos que fijan los lugares como si la identidad fuera manifestación de una mismidad ontológica e inmutable. Se trata, en cambio, de pensar el carácter histórico y relacional de las identidades, en este caso de "la gente del campo". Las nuevas identidades de los jóvenes migrantes habrían sido construidas a lo largo de diferentes posiciones ocupadas en su trayectoria como hijo, miembro de una familia, alumno de la escuela, cosechero en la pampa, peón en una estancia, o simultáneamente en el espacio social, con las experiencias ligadas a las mismas y los discursos que ayudan a conformar dichas identidades. Esto no implica considerarlas como abiertas enteramente, es decir, desligadas de las estructuras, pensando que son volátiles y están sujetas a la voluntad de los individuos, sino reconociendo que son resultados de procesos constructivos.

En las experiencias migratorias se reconstituyen subjetividades, reconocimientos de lo que son ellos mismos y lo que son los otros. Esto conlleva procesos de subjetivación que conducen a que asuman o confronten total o parcialmente, temporal o permanentemente, las locaciones, los lugares demarcados de antemano, "desde afuera", pero que ellos mismos a su vez construyen con sus prácticas y narrativas cambiantes sobre sí mismos.

Finalmente, en relación con la migración, en todas las unidades familiares estudiadas las cartas enviadas por los migrantes ocupaban un lugar importante y movilizaban a los parientes. Cuando no había ningún integrante que supiera leer y escribir, debían proveerse de ayuda para posibilitar la comunicación. En cualquier caso esa correspondencia era 
un bien muy preciado que las familias conservaron, gracias a lo cual tuve acceso a varios de esos documentos en mi investigación.

\section{El movimiento campesino de Córdoba, la identidad campesina y las prácticas de cultura escrita}

En apartados anteriores hemos mencionado la presencia de un actor político y educativo emergente - el Movimiento Campesino de Córdoba (MCC) - , y hemos planteado que sus iniciativas se configuran en el marco de la "lucha por el territorio" y la defensa de la vida campesina frente al avance del agronegocio. Reivindicando derechos, estas organizaciones avanzan en propuestas educativas que se concretan en instituciones que presentan como “escuelas campesinas" (MCC, 2012). ${ }^{11}$

El MCC es una organización de $3{ }^{\text {er }}$ grado constituida por seis "centrales" que nuclean organizaciones zonales de $2 .^{\circ}$ grado, formadas a su vez por comunidades de base, cuyas acciones se desarrollan en el norte de la provincia. Surge en el año 2004 y reúne aproximadamente a mil familias que participan en asambleas a través de delegados. También, la integran más de mil quinientas familias, que se vinculan indirectamente a través de los proyectos que se promueven. Está integrado por campesinos y un grupo de "técnicos" de extracción universitaria que llegaron a fines de los 90 a los territorios,

11 En Cragnolino (2017) puede verse un análisis de a las condiciones que hicieron posible la elaboración del proyecto de una escuela secundaria alternativa (de alternancia, de "gestión social", con participación de las organizaciones y las familias) y su transformación y derivación en sedes de programas de terminalidad de secundaria estatal. Reconocemos en ese artículo los actores participantes, relaciones, sentidos disputados y tensiones que atraviesan estas singulares prácticas educativas que surgieron como proyectos alternativos al oficial pero que en realidad hoy son parte del Sistema Regular de Educación de Jóvenes y Adultos o se constituyen en sedes de Programas para niños/jóvenes (Programa de Inclusión y Terminalidad - PIT-) que no han completado el nivel medio , cuya obligatoriedad fue establecida por la Ley Nacional 26206 del año 2006. colaboraron con los diagnósticos y los procesos organizativos iniciales y coordinan los diferentes espacios formativos y entre ellos los programas educativos oficiales de terminalidad de secundaria semipresencial.

Las reivindicaciones educativas surgen en un contexto de luchas, donde el MCC se va configurando como un actor político provincial, que participa de organizaciones a nivel nacional (Movimiento Nacional Campesino Indígena) e internacionales (Coordinadora Latinoamericana de Organizaciones del Campo, La Vía Campesina). Se desarrollan inicialmente espacios de formación por comunidades, vinculados a cuestiones productivas, sectoriales y políticas, pero también se va construyendo un camino de formas pedagógicas y contenidos compartidos por las organizaciones nucleadas en Argentina, orientadas por las prácticas de otros movimientos consolidados, como el Movimento dos Trabalhadores Rurais Sem Terra (MST) de Brasil.

El MCC se presenta como un espacio que pone en circulación representaciones campesinistas de sujetos que con anterioridad se reconocían como "gente de campo", “criollos", "pequeños productores” y desde hace aproximadamente dos décadas asumen esta nueva identidad. La categoría campesino lo constituye en un sujeto no solo económico, sino también político. Como sujeto económico es identificado por el carácter diversificado de su producción, conocimientos ancestrales acerca de cómo y dónde plantar, qué animales criar y de qué manera hacerlo, cómo utilizar el bosque, el agua, el fuego y manejar los recursos naturales. Saberes antiguos que no se limitan a la producción, sino a la salud (a través, por ejemplo, del uso de hierbas medicinales), organización social (la cooperación-minga) y se trasmiten en y por la práctica. Señalan que estos saberes deben ser preservados, pero que tienen que ser fortalecidos a través de los nuevos conocimientos que aportan los "manos blandas", como denominan a los técnicos provenientes en su mayoría del ámbito universitario. 
En esta convergencia de viejos y nuevos saberes, la agroecología se presenta como una alternativa y una apuesta económica y formativa, y a los campesinos con atributos que los diferencian de los otros productores, en particular, los empresarios que le disputan y expropian las tierras (MCC, 2010).

Aquí adquiere importancia el paso por la Escuela Campesina, a partir de la cual se construye un nuevo sentido de la escolarización y valorización del acceso a la cultura escrita, no ya para facilitar la emigración, sino para seguir viviendo como campesinos, mejorando su producción y constituyéndose como un actor político, avanzar en las alianzas con otros colectivos en busca de una transformación de la vida social.

En la práctica cotidiana y en sus diferentes áreas de trabajo (salud, educación, producción, actividades de organización política, etc.), las organizaciones del MCC despliegan una serie de recursos de cultura escrita: elaboran proyectos para ser presentados ante diferentes organismos públicos y privados de financiamiento y luego informes que dan cuenta del uso de los recursos y las acciones realizadas. En las reuniones recurren a pizarras o afiches, donde sintetizan lo discutido, y en la mayoría de las oportunidades utilizan papeles, porque este recurso facilita el resguardo de los temarios, las discusiones, las propuestas y los acuerdos. También, en algunos casos, llevan registros sobre la producción de los campos comunitarios o sobre el manejo del agua.

Se valen también de documentos que, en el espacio público, les sirven para visibilizar y denunciar sus problemáticas. Elaboran folletos que reparten en marchas o en las inmediaciones de los juzgados cuando se producen las audiencias judiciales que criminalizan a las familias campesinas por los intentos de resguardar su tierra frente a los "nuevos dueños" empresarios que, valiéndose de diferentes argucias, las reclaman como propias.

Los espacios de formación en las distintas áreas, también suponen producción o utilización de materiales escritos, por ejemplo los que se emplean en la formación de las promotoras de salud o en las llamadas "escuelas de género". Durante las clases de las escuelas campesinas se recurre a los "módulos oficiales", material educativo del Programa de Educación Secundaria Semipresencial, que produce la Dirección de Educación de Jóvenes y Adultos. Pero también se valen de los producidos por el mismo MCC (Manual de Producción Campesina; Manual de Organización Comunitaria; Cartillas de salud) a los que se agrega literatura de ficción y ensayos, noticias de periódicos, películas subtituladas, entre otros recursos de cultura escrita.

\section{Reflexiones finales}

En ciertos ámbitos educativos, se suelen calificar los espacios rurales, y en particular los territorios campesinos, como "iletrados". A la hora de explicar el "fracaso educativo" se mencionan, en forma recurrente, la "falta de conocimiento" paterno, y la ausencia de recursos de lectura y escritura; lo que predominaría es el "analfabetismo absoluto" o el "funcional" debido a la ausencia o débil escolarización. De este modo, se señala el "contexto" como factor limitante de las posibilidades de educar, lo que implica, tal como lo señalan Redondo y Thisted (1999) el riesgo de desconocer la posibilidad de que la escuela se constituya en un espacio de producción de aprendizajes relevantes. En nuestros estudios y también en talleres que realizamos con maestros de zonas rurales, los participantes suelen poner en juego nociones cosificadas de pobreza, y esencializaciones de la cultura campesina, a la que se califica de "tradicional", "cerrada", con nulo o escaso vínculo con la cultura escrita. Entendemos que esta caracterización obturaría la posibilidad de conocer el bagaje de saberes que las personas "no letradas" poseen e impide identificar los recursos y espacios de participación en la cultura escrita.

A partir de una numerosa evidencia empírica resultante de nuestros estudios podemos poner en cuestión estas caracterizaciones. Los relevamientos partieron de premisas teóricas que plantean 
que la lectura y la escritura (es decir, la literacidad) son prácticas sociales. No nos detenemos en los procesos cognitivos, sino que desde perspectivas socioantropológicas nos interesa comprender lo que las personas hacen con la escritura y la lectura. Seguimos las propuestas de Pierre Bourdieu y los Nuevos Estudios de Literacidad, donde nunca se considera la lectura y la escritura como dimensiones aisladas o independientes de la vida social, ${ }^{12}$ sino como una práctica social y parte de una trama de relaciones que se reconfiguran en espacios locales y en el tiempo. Se trata de comprender estas prácticas siempre inscriptas en contextos y como producto de determinadas relaciones sociales que es preciso reconocer. Desde estos enfoques, aunque no se maneje el código escrito, se reconoce que las personas participan de eventos y prácticas letradas que se configuraban con relación no solo a los espacios escolares sino que también atañen a la organización doméstica, el trabajo predial, y la vida religiosa y comunitaria.

En el artículo nos enfocamos en la migración como parte de las estrategias de reproducción social puestas en juego por familias campesinas del norte cordobés para mantener o mejorar su posición en el sistema de relaciones de clase (Bourdieu, 1988). Vimos cómo se redefinen dichas estrategias conforme se producen transformaciones estructurales y políticas que reorientan los traslados; así: en una primera etapa, los desplazamientos eran rurales y transitorios, ocupaban mano de obra masculina, que vendía su fuerza de trabajo en las zonas cerealeras; luego tendrán destino urbano, involucrarán a la mayor parte de los integrantes de la familia, sin importar el género, y asumirán, en la mayoría de los casos, un carácter definitivo. Advertimos en este proceso la importancia progresiva que fue adquiriendo la escolarización de los hijos como preparación para la salida del campo y la relevancia que fue ganando el dominio de la lectura y la

12 Según lo han planteado los Nels (de manera destacada Street, 1993, 2003, 2005), la lectura y la escritura no pueden reducirse a habilidades técnicas y personales, por lo tanto autónomas, sino que se encuentran siempre contextualizadas e implicadas en relaciones sociales. escritura, no solo como recurso para acceder a mejores empleos, sino también para defender sus derechos y ganar reconocimiento social.

Destacamos ademáscómo lasestrategias migratorias se articularon en los procesos de configuraciónreconfiguración de identidades campesinas. Estas identidades y prácticas culturales que fueron presentadas en ámbitos educativos como estáticas, ahistóricas e inhabilitantes en términos de participación en la cultura escrita.

En estos procesos de reconfiguración de identidades que analizamos en relación con la lectura y la escritura, pudimos identificar distintos momentos: el primero es cuando las familias campesinas del norte cordobés, hasta la década del 30, lograban cierto autobastecimiento predial, y el acceso a la escolarización estaba limitado solo a aquellas unidades con mayores recursos económicos y sociales, que se movilizaban para la creación y el sostenimiento de los establecimientos educativos. Estas familias pudientes eran las primeras que reconocían la importancia del manejo de "letras y números"; era para ellos un capital que se convertía en signo de prestigio y de diferenciación social. Mientras para la mayoría de los pobladores del campo, esta no era una preocupación que los movilizara ni un recurso que los hijos debían necesariamente manejar para lograr la sobrevivencia cotidiana y generacional. Aquellos en contraste se identificaban como "gente de campo", "poco aspirantes" y "brutos", como lo indicaban en las entrevistas. Esta imagen se reproducía, pues se enseñaba y aprendía no solo las labores, sino también un modo de ser "gente del campo", fundamentalmente "hablando poco... más vale mirando y haciendo" (Raúl, comunicación personal, La Toma, mayo de 1997).

Un segundo momento correspondió a la intensificación de las estrategias migratorias. Esto ocurrió a partir de la década de 1940 e implicó la salida progresiva de los hijos, en el caso de los varones, con el traslado estacional a zonas rurales, y en el de las mujeres, para insertarse como trabajadoras domésticas urbanas. Luego, y cualquiera sea su género, con la política de sustitución de importaciones y la 
constitución del estado de bienestar del gobierno peronista (1946-1955) se observaría el establecimiento en las ciudades.

Para entonces en las familias campesinas del norte de Córdoba se incrementó la incorporación a las escuelas y el manejo de la lectura y la escritura adquiere un nuevo valor. $\mathrm{Va}$ a ser entendido como "un conocimiento práctico" que hace posible el acceso a nuevos trabajos urbanos, la defensa de los derechos frente a los nuevos empleadores y la movilidad social. Este proceso supuso la reconfiguración de la identidad de estos migrantes, ya que ahora no solo era importante ser "trabajador", "honesto", sino que tenía que "estar avispado" y contar con conocimientos que le permitieran afrontar su nueva vida. En este momento el manejo de la lectura y escritura se convirtió en un bien preciado, que incluso acercaría a los hijos establecidos en la ciudad a la escuela de adultos de nivel primario y en algunos casos al secundario.

Mientras tanto en el campo se generalizó progresivamente la escolarización de la mayoría de los hijos. Nadie discutía que el lugar de los niños era la escuela y que saber leer y escribir era fundamental para "ser alguien en la vida", para que "te reconozcan” y para "tener futuro". No solo los testimonios de nuestros entrevistados, sino además las estadísticas educativas muestran claramente esta apuesta y el compromiso que asumieron las familias, ya que en las últimas décadas del siglo xx, el $90 \%$ de los niños estaban escolarizados y para el 2001 ese índice alcanzaba el $98 \%$.

En los comienzos del siglo XXI se hizo presente en el norte de la provincia de Córdoba un nuevo actor político y educativo, el Movimiento Campesino de Córdoba (MCC), que surgió en la "lucha por el territorio" y la defensa de la vida campesina frente al avance del agronegocio. En este proceso, en sus diferentes estrategias y ámbitos de acción, entre ellas las escuelas campesinas, se pusieron en circulación representaciones campesinistas, lo que contribuyó a la reconfiguración identitaria de las familias. Las organizaciones apostaban por que los jóvenes se mantuvieran en el campo y continuaran reproduciendo su vida como campesinos. Ponían en valor ciertos atributos y construían marcadores identitarios que resaltaban el manejo campesino de los recursos naturales (el agua, el monte), las formas organizativas solidarias y los conocimientos sobre la alimentación y la salud. Los saberes propios se revalorizaban y articulaban con nuevos conocimientos que daban lugar a formas de producción agroecológica, a diferencia de los empresarios, que destruían la naturaleza y la vida.

Los múltiples espacios formativos que construyeron la vida del MCC (relativos a la producción, la salud, el género, la organización político-territorial, la articulación intersectorial) y en particular la escuela secundaria campesina se convirtieron en espacios de afirmación identitaria. La escuela, como la llaman "nuestra escuela campesina", adquirió nuevos sentidos; lo mismo ocurrió con las prácticas de lectura y escritura. Como hemos señalado, los distintos espacios constituyeron ámbitos de puesta en juego de prácticas letradas y existía una preocupación particular por el efectivo desarrollo de las habilidades asociadas a ellas, que además debían asumir un carácter crítico.

Hemos hablado en este artículo de una configuración dinámica de la identidad campesina y cómo sus transformaciones estuvieron correlacionadas con cambios en las condiciones estructurales, políticas y simbólicas. La idea fue mostrar que los sujetos se apropian de conocimientos, entre ellos los relativos a la lectura y la escritura, lo cual supone no solo el dominio de un código, sino además la participación en eventos y prácticas que contribuyen a la construcción de referentes identitarios. Esto ocurre a lo largo de su vida, en el marco de diferentes procesos y en el contacto con múltiples sujetos.

Las identidades se modifican, se cuestionan, se contradicen y no se corresponden con la visión estática, culturalista, que muchas veces se despliega desde ciertas políticas y prácticas de la escolarización oficial dedicadas a la ruralidad y que aun con la declaración de buenas intenciones terminan encerrando a los niños y jóvenes campesinos en el 
"círculo" de la pobreza y el analfabetismo, frente al cual habría muy poco por hacer.

La invisibilización de los recursos de cultura escrita y de la participación en múltiples eventos y prácticas por parte de las familias campesinas del norte de Córdoba se hizo evidente en este trabajo etnográfico gracias a una perspectiva teórica y metodológica que implicó no sólo mirar "desde arriba", sino también "mirar desde abajo", ${ }^{13}$ para ver qué es lo que sucede en las escuelas. Nos preguntamos cómo esta diversidad propuesta por las políticas fue significada por los maestros, qué estrategias se pusieron en juego; cómo se identificó a los niños del campo, partiendo de la hipótesis de si con sus prácticas no estarían contribuyendo a la construcción de identidades subalternizadas, como lo señalara Novaro (2011). Por supuesto, no estamos tratando de culpabilizar a los maestros, sino de reconocer cómo ellos también participan de la construcción de las identidades de los niños y familias del campo y cuáles son las condiciones sociales de producción de muchas representaciones desvalorizantes. Sobre todo, si pensamos que la mayoría de los docentes del norte cordobés provienen de las mismas familias campesinas.

En este sentido advertimos que hay que trabajar para modificar y fortalecer las escuelas públicas rurales, y señalamos que esto nos compromete como miembros de las universidades públicas. Tal como lo hemos manifestado en múltiples oportunidades, y que se refuerza con las medidas de ajuste y destrucción del sistema de educación pública que en este momento plantea el gobierno

13 Las expresiones: mirar desde arriba y mirar desde y hacia abajo son planteadas en la historia social, por Edward P. Thompson (1995) y Carlo Ginzburg (1991), entre otros, y son retomados como premisas teóricas y epistemológicas por la etnografía analítica latinoamericana, cuyo principal referente es Elsie Rockwell, de México, y en la que se formaron nuestras maestras argentinas Elena Achilli y María Rosa Neufeld. Esta perspectiva continúa y se multiplica a través de la producción de diferentes equipos que constituimos la Red Investigadores en Antropología y Educación (RIAE). argentino, desde la investigación, la docencia y la extensión universitarias, debemos asumir el desafío de participar en todo lo que queda pendiente para transformar con sentido progresista las escuelas del campo y formar a sus maestros.

\section{Referencias}

Barton, D. e Ivanic, R. (Eds.) (1991). Writing in the community (vol. 6). Newbury Park: Sage publications.

Barton, D. y Hamilton, M. (1998). Local literacies: reading and writing in one community. Londres y Nueva York: Routledge. https://doi.org/10.26512/les.v6i0.9483

Bourdieu, P. y Passeron, J.-C. (1977). La reproducción. Elementos para una teoría del sistema de enseñanza. Barcelona: Laia.

Bourdieu, P. (1988). La distinción. Criterios y bases sociales del gusto. Madrid: Taurus.

Bourdieu, P. (1991). El sentido práctico. Madrid: Taurus.

Bourdieu, P. (2011). Las estrategias de reproducción social. Buenos Aires: Siglo XXI.

Cassany, D. (2006). Tras las lineas. Sobre la lectura contemporánea. Barcelona: Anagrama.

Cragnolino, E. R. (2009). Condiciones sociales para la apropiación de la cultura escrita en familias campesinas. En J. Kalman y B. Street (Coords.), Lectura, escritura y matemáticas como prácticas sociales: Diálogos con América Latina (pp. 156-170). México: Siglo xxI. https://doi.org/10.1590/ s0102-46982010000200019

Cragnolino, E. R. (2011). Contribuciones de una perspectiva sociológica crítica y de la etnografía analítica a la formación de maestros rurales. En E. Miranda y N. Bryan, $(R e)$ pensar la educación pública. Aportes entre Argentina y Brasil (pp. 271-288). Córdoba: Editorial FFYH-UNC. https://doi.org/10.2307/j.ctv86dgqn. 11

Cragnolino, E. R. (2013). Access to written culture as part of the social reproduction strategies of rural families in Cordoba (Argentina). En J. Kalman y B. Street, Literacy and numeracy in Latin America: Local perspectives and beyond (pp. 38-51). Nueva York: Routledge.

Cragnolino, E. (2017). Desde escuelas rurales primarias a proyectos de escolarización secundaria campesina. Tensiones y disputas por educación pública en Córdoba. En B. Mancano-Fernandes y C. Molina (Orgs.), Dossier en Educação \& Sociedade: Revista de Ciências da Educação, 38(140), 671-688, CEDES-UNICAMP, Campinas, sP. 
Ginzburg, C. (1991). El queso y los gusanos. Barcelona: Muchnik Editores, s. A.

Hall, S. (2003). Introducción: ¿Quién necesita «identidad»? En S. Hall y P. du Gay (Eds.), Cuestiones de identidad (pp. 13-39). Buenos Aires: Amorrortu.

Kalman, J. (2004). Saber lo que es la letra. México: Siglo XXI.

Movimiento Campesino de Córdoba (2010). Manual de producción campesina. Córdoba: Gráfica 29 de Mayo.

Movimiento Nacional Campesino Indígena (2012). Derecho a la educación campesino indigena. Córdoba: Gráfica 29 de Mayo.

Novaro, G. (2011). Introducción. Interculturalidad y educación. Reflexiones desde las experiencias formativas de niños indígenas y migrantes. En G. Novaro (Coord.), La interculturalidad en debate. Experiencias formativas y procesos de identificaciones en niños indigenas y migrantes (pp. 15-33). Buenos Aires: Biblos. https://doi.org/10.5902/2236672511219

Redondo, P. y Thisted, S. (1999). Las escuelas en los márgenes. Realidades y futuros. En A. Puiggrós, En los límites de la educación. Niños y jóvenes de fin de siglo. Buenos Aires: Homo Sapiens. https://doi. org/10.1590/s1517-97021999000100003
Street, B. (1993). Cross-cultural approaches to literacy. Cambridge: Cambridge University Press.

Street, B. (2003). The limits of the local-'autonomous' or 'disembedding'? International Journal of Learning, 10, 2823-2828.

Street, B. (2005). Recent applications of New Literacy Studies in educational contexts. Research in the Teaching of English, 39(4), NCTE, 417-423.

Thompson, E. (1995). Costumbres en común. Barcelona: Crítica-Grijalbo-Mondadori.

Zavala, V. (2002). (Des)encuentros con la escritura: escuela y comunidad en los Andes peruanos. Lima: Red para el Desarrollo de las Ciencias Sociales en el Perú. https://doi.org/10.21678/apuntes.66.601

Zavala, V. (2005). Un Perú que lee, ¿un país que cambia? una mirada a los mitos de la lectoescritura. Boletín de Foro Educativo, 6(2), Disponible en: http://www.foroeducativo.org.pe/comunicaciones/revista6/zavala.htm

Zavala, V. Niño-Murcia, M. y Ames, P. (Org.). (2004). Escritura y sociedad: nuevas perspectivas teóricas y etnográficas. Lima: Red para el Desarrollo de las Ciencias Sociales en el Perú.

How to reference this article: Cragnolino, E. R. (2019). Estrategias migratorias, reconfiguraciones de identidades campesinas y participación en la cultura escrita. Íkala, Revista de Lenguaje y Cultura, 24(2), 233-247. DoI: 10.17533/udea.ikala.v24n02a03 